\section{THE IMPACT OF FAMILY-WORK IMBALANCE ON SELF- PERCEIVED HEALTH: MODIFYING EFFECT OF SOCIAL SUPPORT}

${ }^{1}$ Hale Arik Tasyikan*, ${ }^{2}$ Yucel Demiral. ${ }^{1}$ Yeditepe University, Istanbul, Turkey; ${ }^{2}$ Dokuz Eylul University, Izmir, Turkey

\subsection{6/oemed-2018-ICOHabstracts. 1662}

Introduction Work and family imbalance is an important determinant of worker's health. The research on the effects of multiple roles on health in developing countries is scarce. The aim of this study was to investigate the effect of work-family imbalance on self-perceived health $(\mathrm{SPH})$ and to assess the modifying effect of job insecurity (JI), social support at home (SSH), and at work (SSW).

Methods This is a population-based cross-sectional study. The study sample was randomly derived from employed individuals aged 30-64 who participated in 'Balcova Heart Project'. 191 men and 216 women were included in the analyses. Dependent variable was SPH and main independent variables were work-family conflict (WFC), and family-work conflict (FWC). JI, SSH and SSW were considered as possible effect modifiers. Mainly logistic regression models were used.

Results Mean age was $41.9 \pm 6.3$ and $39.4 \pm 6.3$ for men and women. Women were more likely to work in white-collar jobs, more educated and have better economic status perception than men. FWC and WFC were independently associated with increased odds of poor SPH [age adjusted odds ratios $(\mathrm{OR})=2.92$ (1.47-5.78), and 2.38 (95\% CI: 1.22 to 4.67$)$ respectively] for women, but there was no significant association for men. In advanced analyses, both SSW and SSH were found to be effect modifiers of the association between FWC and $\mathrm{SPH}$ in women $(\mathrm{p}<0.001)$. However, the significant association of WFC with SPH disappeared after the adjustment with SSW, therefore, SSW considered to be a confounder for the associations of WFC. Only the association between JI and $\mathrm{SPH}$ was significant [odds ratio $(\mathrm{OR})=2.52(1.22-5.21)]$ in men.

Discussion Both FWC and WFC are important determinants of worker's psychosocial health. Further studies should explore effective population prevention strategies to diminish FWC and WFC, especially in women in developing countries.

\section{INDEPENDENT RELATIONS OF PHYSICAL DEMANDS AND PSYCHOSOCIAL JOB RESOURCES WITH MUSCULOSKELETAL COMPLAINTS: A LONGITUDINAL STUDY}

1J Vandeneede*, 'B Van de Ven, ${ }^{2} \mathrm{P}$ Vlerick, 'E Clays. 'Ghent university, Public Health, Ghent, Belgium; ${ }^{2}$ Ghent University, Department of Personnel Management, Work and Organisational Psychology, Ghent, Belgium

\subsection{6/oemed-2018-ICOHabstracts. 1663}

Introduction Academic research has elaborated the impact of physical demands (PD) on musculoskeletal health for employees in physically demanding jobs. Studies investigating musculoskeletal complaints (MSC) are mainly cross-sectional, which is a limitation to draw conclusions on causality. In addition the role of psychosocial factors on the work floor for health is receiving more attention from different studies. This study was designed to examine longitudinally whether psychosocial job resources (job autonomy and social support) and physically demanding activities at work have independent effects on MSC 12 months later.

Methods Results were based on a study including employees from a technology company in Belgium. For 457 persons full information (baseline and at one year follow-up) was available. The exposure measurements used in the study (PD and psychosocial job resources) were obtained from 'the work design questionnaire'. A four-item scale concerning MSC in the previous six months was applied. Multiple linear regression analyses were conducted.

Result Participants were between 22 and 67 years old (mean age was 48.8 years; SD 10.3). Men were highly represented (92.6\% men) and $54.9 \%$ of the sample had a lower educational background. The independent relations of PD and psychosocial factors were tested in the final model after adjusting for gender, age, language, educational level and baseline MSC. Regression analyses indicated that PD were associated with greater MSC, 12 months later. Only work method autonomy had a negative effect on MSC. Social support, work decision autonomy and work scheduling autonomy had no significant effect.

Discussion The first conclusion of the study was the confirmation of a positive relation between PD at work and MSC over time. The second conclusion was the independent negative effect of work method autonomy on MSC. The main strength of the study was its longitudinal design. A possible limitation was the underrepresentation of women.

\section{OCCUPATIONAL EXPOSURES AND PSYCHOLOGICAL SYMPTOMS AMONG FIRE FIGHTERS AND POLICE DURING A MAJOR WILDFIRE: THE CARMEL COHORT STUDY}

${ }^{1,2}{ }^{2}$ ED Amster*, ${ }^{1} S S$ Fertig, ${ }^{2} \mathrm{M}$ Green, ${ }^{2} \mathrm{R}$ Carel. ${ }^{1}$ University of Haifa, School of Public Health, Department of Occupational Health, Israel; ${ }^{2}$ Harvard University, T.H. Chan School of Public Health, USA

\subsection{6/oemed-2018-ICOHabstracts. 1664}

Introduction The Carmel fire resulted in the death of 45 rescue workers. Little research exists on the health risks to emergency responders during forest fires and the immediate and long term psychological impact from occupational stressors. There is no prospective cohort studying the long term mental health effects among first responders.

Methods A retrospective exposure assessment was performed on 300 first responders, assessing personalised exposure to occupational stressors such as severe lack of sleep, fear for personal safety, and witnessing death of other rescue workers. Frequency of psychological symptoms and mental health diagnoses were assessed among the cohort prospectively over a three year period. Unpaired two sample t-test compared mean exposures and symptom frequency for firefighters and police separately and together. Chi-square estimates of Odds Ratio and 95\% CI are provided for odds mental health outcomes 
Results Occupational stress was extremely high; the average length of time working without rest was 18.4 hours. $57 \%$ responded that their personal safety was severely at risk, and $49 \%$ felt at severe risk of losing their life. 24\% (17\% of firefighters and $44 \%$ of police) reported at least one acute stress related symptom following the fire, while $10 \%$ (6\% of firefighters and $21 \%$ of police) continue to have PTSD 1 year following the fire. A strong inverse correlation between level of training, years of experience, and availability appropriate protective equipment, baseline health status exists with psychological outcomes. There was a strong positive correlation between availability of occupational health services, proximity to fire, risk perception with psychological outcomes.

Conclusion First responders were exposed to significant occupational stressors during the Carmel fire. These exposures and organisational factors increased the odds of acute stress disorder and PTSD. Further research is needed on the residual mental health effects among emergency responders from occupational stressors, and efficacy of preventative policies.

\section{PREVALENCE OF MENTAL ILLNESS AMONG METALWORKERS IN SÃO PAULO, BRAZIL}

1,2PM Felicio*, 1,3 EP Chagas.

10.1136/oemed-2018-ICOHabstracts. 1665

\section{${ }^{1}$ Belgo Bekaert Arames, São Paulo, Brazil}

${ }^{2}$ Bridon Bekaert Roupes Group, São Paulo, Brazil; ${ }^{3}$ Belgo Mineira Brasil, Contagem MG, BraziIntroduction Mental health status is related to work context and content. There are many stressful conditions at work associated to negative effects on workers' health. According to the World Health Organisation (WHO), common mental disorders affect more than $30 \%$ of employed workers. Mental and behavioural disorders are the third main cause of social security benefits payment in Brazil. This study aims to raise the prevalence of mental illness among employees of two metallurgical companies and differences between them.

Methods A descriptive cross-sectional study was carried out in two companies located in São Paulo State, Brazil, in 2016. Participants were 440 workers - 146 from company A and 294 from company B. They answered a sociodemographic questionnaire and the WHO's Self-Report Questionnaire with 20 questions about mental symptoms (SRQ-20). Cases were participants with seven or more positive answers in SRQ-20.

Results Company A produces wires for the construction industry and $\mathrm{B}$ is a metallurgical producer of steel cables for the oil and mining industry. The prevalence of mental illness among the participants was $15.17 \%$ (company A) and $12.28 \%$ (company B). There was a higher percentage of mental symptoms among company A women (66\%) than company $\mathrm{B}^{\prime}$ (26.6\%). About education, participants with more than 12 school years presented more mental illness in company B $(36.8 \%)$ than company A $(19.5 \%)$. In general, 'to feel nervous, tense, worried', and 'sleep badly' were most common positive answers in both groups.

Discussion Mental illness prevalence was similar among both groups and results were similar to other studies. Company A women and Company B high education workers would be at higher risk for mental problems. It's necessary to provide medical and psychological support to cases and preventive actions should be offered to promoting health among employees of those companies.

\section{ASSOCIATION BETWEEN LONG WORKING HOUR AND JOB STRESS AND DEPRESSION AMONG EMPLOYEES AT GRID COMPANY IN CHINA}

DAI Junming, LI Ja, SHU Chang, WU Ling, GAO Junling, FU Hua. School of Public Health, Fudan University, China

\subsection{6/oemed-2018-ICOHabstracts. 1666}

Objective This study was to understand the current situation of long working hours and identify the association of long working hours and job stress and depression among workers in state grid company.

Methods The project was done using the cross-sectional survey. All questionnaires were completed by self-administered with informal consent. Employees whose weekly working hours was 40 or less were set as the reference group, and the others were categorised with a gradient of 10 hours for grouping; the PHQ-9 scale used to assess depression, the job demand-control (JDC) Model used to evaluate job stress. And SPSS software to analyse data, multivariate Logistic analysis were performed to identify the association between long working hours and job stress, depression.

Results there were 1069 staff attend this survey and 63.0\% employee with standard working hour which they work for 40 hours a week. And 18.8\% employees with 41-50 hours a week, and $12.9 \%$ workers with 51-60 hours a week, only $5.2 \%$ employees worked over 60 hours a week. There were $63.2 \%$ workers with job stress by job demand control ratio over $1.0 \%$ and $66.9 \%$ employee self-reported with depression by PHQ-9 over 5 . The association between increasing weekly working hours and occupational stress and depression was statistically significant. Compared to the reference group, for those who worked more than 60 hours per week, the odds ratio of depression was 3.25 (95\% CI: 1.43 to 7.40$)$ times increased; the odds ratio of occupational stress was 4.34 (95\% CI: 1.19 to 15.92 ) times increased; the odds ratio of moderate-severe and severe depressive symptoms was 11.18 (95\% CI: 1.21 to 115.05 ) times increased.

Conclusions Long working hours can significantly increase the risk of job stress and depressive symptoms among the national grid company employees. When their weekly working hours exceeds 60, long working hours will be the independent risk factor for both job stress and depression.

\section{EVOLUTION OF A YOUNG WORKER TRAINING CURRICULUM: TAKING SAFETY FROM THE CLASSROOM TO THE BREAK ROOM}

${ }^{1,2} \mathrm{DS}$ Rohlman*, ${ }^{3} \mathrm{M}$ Parish, ${ }^{4} \mathrm{DL}$ Elliot, ${ }^{5} \mathrm{G}$ Hanson. ${ }^{1}$ Occupational and Environmental Health, University of lowa, lowa City, IA USA; ${ }^{2}$ Healthier Workforce Centre of the Midwest, University of lowa, lowa City, IA USA; ${ }^{3}$ Confluence Health, Wenatchee, WA, USA; ${ }^{4}$ Health Promotion and Sports Medicine, Oregon Health and Science University, Portland, OR USA; ${ }^{5}$ Johns Hopkins University, Baltimore, MD USA

\subsection{6/oemed-2018-ICOHabstracts. 1667}

Introduction Young Workers (14-24) represent a valuable aspect of the workforce. However, limited work experience and developmental factors predispose young workers to an increased risk of occupational injuries compared to their older counterparts. Although traditional safety training has targeted the identification of hazards (e.g., chemical exposures, physically demanding work), it typically does not address work environment/organisational factors that can also impact health 